\title{
NARZĘDZIA STOSOWANE W PROJEKTOWANIU PARAMETRYCZNYM W ARCHITEKTURZE KRAJOBRAZU
}

\author{
Marzena Suchocka ${ }^{\bowtie}$, Aleksandra Widaj, Kinga Kimic \\ Wydział Budownictwa i Inżynierii Środowiska, Szkoła Główna Gospodarstwa Wiejskiego w Warszawie, Warszawa
}

\begin{abstract}
STRESZCZENIE
W dobie cyfryzacji projektowanie parametryczne stwarza nowe możliwości jego zastosowania w dziedzinach takich jak architektura i design oraz architektura krajobrazu. Niezbędne są jednak do tego narzędzia, które nie tylko mogą ułatwić sam proces projektowania, ale też zmniejszyć jego czasochłonność. Celem niniejszego artykułu jest przegląd oprogramowania wykorzystywanego do projektowania parametrycznego wspomagającego pracę architektów krajobrazu. Ocenie poddano wybrane, najbardziej popularne programy i wtyczki stosowane przez architektów i designerów, z których pośrednio korzystają także architekci krajobrazu, a także oprogramowanie specjalnie stworzone do stosowania w pracy architekta krajobrazu. Większość omawianego oprogramowania ma opcje projektowania parametrycznego, dotyczą one jednak tylko wybranych elementów. Nie ma w chwili obecnej jednego wielofunkcyjnego programu dającego możliwość kompleksowego zastosowania opcji projektowania parametrycznego do wszystkich aspektów składających się na kompleksowy projekt z zakresu architektury krajobrazu, która jest interdyscyplinarna. Z tego powodu architekci krajobrazu są zmuszeni do samodzielnego łączenia funkcji kilku rodzajów oprogramowania. Stanowi to znaczne utrudnienie w przeprowadzeniu procesu projektowego.
\end{abstract}

Słowa kluczowe: projektowanie parametryczne, modelowanie parametryczne, cyfrowe narzędzia projektowania, projektowanie, architekt krajobrazu

\section{WSTĘP}

Projektowanie parametryczne, nazywane też komutacyjnym, jest metodą cyfrową opartą na algorytmach, które zdefiniowane są w przystosowanym do tego celu oprogramowaniu parametrycznym. Umożliwia ono wyrażanie parametrów i reguł, które koduja, definiują i wyjaśniają związek między zamiarem projektowym a jego realizacją (Woodbury, 2010; Jabi, 2013; Schumacher, 2016). Projektowanie parametryczne pozwala na wykorzystanie rozmaitych wersji interakcji geometrycznych przy jednoczesnym ich szybkim generowaniu w projektach 3D. Powstają w ten sposób modele parametryczne - o nieskończonej liczbie wersji - bę- dące siecią powiązań geometrycznych, które mogą być następnie przetwarzane w różnych kontekstach przestrzennych. Wprowadzenie wielu zmiennych dla przyjętych parametrów w danym wzorze matematycznym umożliwia wygenerowanie atrakcyjnych koncepcji, przy czym w każdym z rozwiązań wszystkie elementy składowe pozostają ze sobą ściśle powiązane.

Projektowanie parametryczne jest stosowane w wybranych gałęziach przemysłu (samochodowym, lotniczym, okrętowym), a także projektowaniu produktów przemysłowych od lat 80. XX wieku (Menges, 2006). W architekturze ma zastosowanie od niemal 30 lat, czego przykładami sa jedne z pierwszych budowli wykonanych $\mathrm{z}$ użyciem tego narzędzia, jak Terminal 
Waterloo w Londynie (1990-1993) i fasada domu handlowego Weltstadthaus w Kolonii (1999-2005) (Januszkiewicz，2012，2016; Schumacher，2016). Podstawą jego zastosowania jest wspomaganie procesu projektowania konstrukcji budynków (Białozor i Górski, 2018) i elewacji (Nassery i Sikorski, 2018). Projektowanie parametryczne jest również przydatne w urbanistyce przy tworzeniu scenariuszy opartych na generowaniu nowych form urbanistycznych przy określonym zestawie fundamentalnych zasad przetwarzanych przez cyfrowe medium. Modelowanie parametryczne może stanowić w tym przypadku narzędzie symulacji przestrzennej $\mathrm{w}$ urbanistyce i procesach koncepcyjnego tworzenia planów zagospodarowania terenu (Schumacher, 2009; Amoroso, 2012; Nawrocka, 2013). Potrzebe zastosowania informatyki w procesie projektowania zauważono już dawno, o czym może świadczyć chociażby konferencja Digital Landscape Architecture (DLA) organizowana regularnie od 2004 roku.

Wiele parametrów i liczne relacje zachodzące między parametrami to również cechy krajobrazu. Projektowanie parametryczne znajduje zastosowanie i w tym przypadku, wspomagając szybkie tworzenie rozmaitych form w przestrzeni jako wyrażenie idei projektowych $\mathrm{z}$ zachowaniem złożoności relacji i uwarunkowań istniejących w krajobrazie przyrodniczym lub miejskim. Może ono służyć również jako narzędzie do analizy krajobrazu i projektowania zielonej infrastruktury, wykorzystując matematyczne modele fizycznych procesów, algorytmów i analizy statystycznej na wszystkich etapach procesu projektowania, aby tworzyć strategie np. podnoszące wydajność ekologiczną stosowanych rozwiązań (Charalampidis i Tsalikidis, 2015). W ostatnich latach tworzone jest także oprogramowanie umożliwiające architektom krajobrazu korzystanie z tego narzędzia w coraz bardziej przystępny sposób i jego wykorzystanie do projektowania obiektów w różnej skali (Gerber, 2007; Paulson, 2017).

Głównym założeniem badań w niniejszym artykule jest porównanie możliwości, jakie daje projektowanie parametryczne $\mathrm{w}$ dobie cyfryzacji, poprzez ocenę przydatności różnych narzędzi $\mathrm{w}$ dziedzinach takich jak architektura i design oraz architektura krajobrazu.

\section{MATERIAt I METODY}

W artykule przeanalizowano narzędzia dostępne w Polsce i na świecie stosowane do celów projektowania parametrycznego oraz ich przydatność w architekturze, sztuce i designie. Badania objęły porównanie ośmiu najczęściej wykorzystywanych programów do projektowania $\mathrm{w}$ zakresie trzech aspektów: stopnia trudności obsługi programu, dostępności cenowej, języka programowania. Analizie poddano także przydatność narzędzi projektowania parametrycznego pod kątem dostosowania ich do potrzeb architektów krajobrazu. Następnie ocenione zostały trzy programy, które rekomendowane są przez Amerykańskie Towarzystwo Architektów Krajobrazu (American Society of Landscape Architects - ASLA). Ze względu na specyfikę obiektów architektury krajobrazu związaną $\mathrm{z}$ udziałem roślinności uwzględniono narzędzia wspomagające prace projektanta i zawierające następujące elementy: biblioteki roślin, glokalizację, nakładki dotyczące nawadniania, BIM, a także czy dostępny jest interfejs w języku polskim. Badania prowadzono w celu rozpoznania, czy programy mają charakter kompleksowy umożliwiający projektowanie parametryczne skomplikowanych obiektów architektury krajobrazu oraz jakie narzędzia wspomagają i dopełniają pracę przy projektowaniu parametrycznym.

\section{Narzędzia projektowania parametrycznego stosowane $w$ architekturze krajobrazu}

Istnieją bardzo różne języki skryptów, które są wykorzystywane w programowaniu. Zasadniczy podział następuje między graficznym językiem programowania a tekstowym, który wymaga dużych umiejętności programistycznych. Programy wykorzystujące graficzny język programowania mają więc większy potencjał $\mathrm{w}$ zakresie ich zastosowania $\mathrm{w}$ procesie projektowania obiektów architektonicznych, małej architektury czy elementów designu. Do narzędzi najczęściej wykorzystywanego w projektowaniu parametrycznym zaliczyć należy następujące programy i wtyczki ${ }^{1}$ :

- CATIA - znane oprogramowanie, jeden z najbardziej rozbudowanych i wszechstronnych programów wspomagających prace inżynierskie (również

${ }^{1}$ Dodatkowy moduł do programu komputerowego, który rozszerza jego podstawowe możliwości. 
w przemyśle i lotnictwie) - począwszy od koncepcji aż po dokumentację techniczną. Narzędzie to jednak ze względu na wysoką cenę i wysoki poziom skomplikowania rzadko zyskuje zastosowanie w projektowaniu architektury. Było wykorzystane np. przez Franka Gehry'ego podczas pracy nad projektami: Guggenheim Muzeum w Bilbao oraz pomnik Złotej Ryby w Barcelonie. Na podstawie silnika CATIA firma Gehry Technologies stworzyła Digital Project - własne oprogramowanie do projektowania parametrycznego.

- Autodesk 3DS Max - program ten umożliwia modelowanie, animacje, symulacje i renderingi. Używany jest głównie w grach, ale również w projektowaniu wnętrz. Program ten stosuje modyfikacje i powiązania parametryczne, żeby kontrolować geometrie modeli oraz umożliwia określenie ich funkcjonalności.

- Autodesk Maya - oprogramowanie używane do tworzenia interaktywnych aplikacji 3D, animacji, seriali telewizyjnych i efektów specjalnych. Pozwala na wykonywanie złożonych obliczeń oraz wysokiej jakości narzędzi do renderowania obiektów i elementów tworzonych w projektach.

- Autodesk Evit - oprogramowanie przeznaczone dla architektów i konstruktoów, dzięki któremu można tworzyć trójwymiarowe modele parametryczne. Ma system BIM $^{2}$, dzięki czemu zmiany wprowadzone $\mathrm{w}$ jednym miejscu automatycznie sa aktualizowane w innych widokach, przekrojach itp. Ułatwia to współpracę między poszczególnymi zespołami projektowymi oraz eliminuje wiele błędów i liczbę poprawek.

- Generative Components - oprogramowanie stworzone przez Bentley Systems. Użytkownicy moga zarówno konwencjonalnie modelować geometrię, jak i stosować projektowanie parametryczne, tworząc algorytmy określające powiązania między poszczególnymi elementami. Oprogramowanie to obsługuje takie same formaty plików jak programy firmy Autodesk, Rhino i inne. Co więcej, może również integrować się z systemami BIM. Jest ono głównie stosowane przez architektów i konstruktorów.
- Rhino - Grasshopper 3D - wtyczka do programu Rhino, która ma wizualny język programowania i tworzenia geometrii. Opiera się na wykresach, które definiują określone funkcje i parametry, co bezpośrednio wpływa na wygląd graficzny projektowanej geometrii. Aby z niej korzystać, nie trzeba znać specjalistycznego języka programowego, ponieważ wtyczka umożliwia wizualne metody generowania ciągu poleceń.

- Marionette - Vectorworks - narzędzie do tworzenia skryptów stosowane m.in. przez architektów, konstruktorów, architektów krajobrazu i inżynierów. Umożliwia tworzenie algorytmów na interaktywnych parametrach, automatyczne rysowanie $2 \mathrm{D}$, modelowanie 3D i przepływ pracy BIM z oprogramowaniem Vectorworks. Ma zastosowanie do tworzenia całkowicie niezależnych obiektów parametrycznych, które można również wkomponować do istniejących projektów.

- Modelur - SketchUp - wtyczka do modelowania przestrzeni publicznych do programu SketchUp. Oferuje modelowanie środowiskowe, tzn. budowanie przestrzeni użytkowej przez kluczowe parametry miejskie, takie jak powierzchnia budynku brutto lub liczba kondygnacji (zamiast wysokości i szerokości budynków). Dodatkowo oblicza główne wskaźniki urbanistyczne, umożliwiając szybką i sprawną ocenę oraz pracę nad wybranymi obszarami miejskimi. Jest to narzędzie stosowane najczęściej przez urbanistów w kontekście gospodarki przestrzennej.

Omówione oprogramowania stosowane w projektowaniu parametrycznym porównano ze sobą, przyjmując jako kryterium przydatności dla projektantów odniesienie do trzech aspektów: stopnia trudności obsługi programu, dostępności cenowej oraz języka programowania. W każdym z nich dokonano oceny, przyjmując dwustopniową skalę. $\mathrm{W}$ ocenie stopnia trudności: 1 pkt oznacza dużą łatwość obsługi dla potencjalnego użytkownika, a 2 pkt - znaczną trudność w zakresie obsługi nawet dla wyspecjalizowanego użytkownika; w przypadku dostępności cenowej: 1 pkt oznacza konieczność wniesienia opłaty

\footnotetext{
${ }^{2}$ Modelowanie informacji o budowaniu (Foremny, 2013).
} 
za licencje poniżej 20 tys. PLN, a 2 pkt - powyżej 20 tys. PLN; w przypadku języka programowania: 1 pkt oznacza dodatkowy graficzny język programowania (co stanowi duże ułatwienie i przyspieszenie prac projektowych), a 2 pkt - tekstowy język programowania (wymagający większego nakładu czasu i pracy $\mathrm{w}$ procesie projektowym). Wyniki analiz przedstawiono $\mathrm{w}$ zestawieniu tabelarycznym (tab. 1).

Wyniki porównania wskazują na największe potencjalne zastosowanie programów, które uzyskały 3 pkt (Autodesk 3ds Max, Rhino - Grasshopper 3D, Marionette-Vectorworks), ponieważ są zarówno dostępne cenowo, jak i stosunkowo łatwe w obsłudze, a dodatkowo mają wbudowany graficzny język programowania znacznie ułatwiający pracę. Należy jednak zaznaczyć, iż wybór konkretnego oprogramowania wymaga uwzględnienia specyfiki każdego $\mathrm{z}$ programów lub wtyczek, a także pozostałego oprogramowania, z jakim będzie kompatybilne, a które jest użytkowane przez danego projektanta. Przedstawione przykłady nie wyczerpują tematu oprogramowania zawierającego możliwość projektowania parametrycznego. Wiele programów jest opracowanych tylko i wyłącznie do konkretnych zastosowań, jednak dużą część można wykorzystywać interdyscyplinarnie, co jest szczególnie istotne m.in. w kreowaniu przestrzeni miejskiej. Wybór narzędzi zależy od potrzeb, wizji oraz możliwości projektantów.

\section{Narzędzia programowe stosowane w architekturze krajobrazu}

W przypadku oprogramowania przeznaczonego do kształtowania krajobrazu coraz powszechniej stosuje się wtyczki do programów stosowanych przez projektantów obiektów architektonicznych, ale także oprogramowanie odpowiadajace potrzebom architektom krajobrazu. Popularne stają się również platformy internetowe ${ }^{3}$, na których można udostępniać swoje prace, jak i pobierać pliki zamieszczane przez innych użytkowników. Prowadzi to do wymiany doświadczeń na zasadzie ekonomii współdzielenia (ang. sharing economy).

Amerykańskie Towarzystwo Architektów Krajobrazu (ASLA) wyróżniło trzy programy wiodące $w$ architekturze krajobrazu i są to: KeySCAPE LandCADD, Land F/X oraz Vectorworks Landscape (ASLA, 2017). Programy te wyróżniają następujące komponenty przypisane do specyfiki projektowania obiektów architektury krajobrazu: projektowanie

Tabela 1. Ocena przydatności programów z możliwością projektowania parametrycznego

Table 1. Evaluation of the usability of programs with the parametric design option

\begin{tabular}{lcccc}
\hline $\begin{array}{l}\text { Nazwa programu / wtyczki } \\
\text { Name of program / plugin }\end{array}$ & $\begin{array}{c}\text { Stopień trudności } \\
\text { Difficulty level }\end{array}$ & $\begin{array}{c}\text { Dostęność cenowa } \\
\text { Price availability }\end{array}$ & $\begin{array}{c}\text { Jezyk programowy } \\
\text { Program language }\end{array}$ & $\begin{array}{c}\text { Suma } \\
\text { Sum }\end{array}$ \\
\hline CATIA & 2 & 2 & 2 & 6 \\
\hline Autodesk 3ds Max & 1 & 1 & 1 & 3 \\
\hline Autodesk Maya & 1 & 1 & 2 & 4 \\
\hline Autodesk Revit & 1 & 1 & 2 & 4 \\
\hline Generative Components & 1 & 2 & 1 & 3 \\
\hline Rhino - Grasshopper 3D & 1 & 1 & 1 & 3 \\
\hline Marionette - Vectorworks & 1 & 1 & inne & 2 \\
\hline Modelur - SketchUp & 1 & 1 & other & 3 \\
\hline
\end{tabular}

\footnotetext{
${ }^{3}$ Platformy internetowe umożliwiają wzajemne interakcje użytkowników w Internecie zazwyczaj w celu wymiany bądź sprzedaży usług, treści czy produktów.
} 
kompleksowego nawodnienia, możliwość pracy jednocześnie $\mathrm{w}$ widoku 2D i 3D oraz oprogramowanie $\mathrm{BIM}^{4}$.

Do narzędzi oprogramowania uwzględniającego projektowanie parametryczne stosowanych przez architektów krajobrazu zaliczyć należy następujące:

- KeySCAPE LandCADD - jest to program, w którym wprowadza się dane na zasadach stosowanych w oprogramowaniu projektowym CAD. Umożliwia modelowanie gruntu oraz uwzględnia koordynaty GPS. Zawiera bibliotekę obejmującą 8 tys. roślin, a w trakcie projektowania można wykonywać symulacje ich wzrostu. Pozwala również na projektowanie nawodnienia uwzględniające oszacowanie wydatków wody oraz pokazujące przepływ wody w krajobrazie. KeySCAPE LandCADD podczas projektowania 2D automatycznie generuje obraz 3D wykonanej pracy. Program zawiera BIM, a także możliwość bezpośredniego importowania danych do programu Autodesk Revit oraz do AutoCAD.

- Land F/X - zawiera obszerne biblioteki roślin (ponad 20 tys.) i innych elementów. W odróżnieniu od KeySCAPE LandCADD zawiera je w chmurze, dzięki czemu można na bieżąco dzielić się nimi $\mathrm{z}$ innymi użytkownikami i uzyskiwać nowe biblioteki. Program współpracuje $\mathrm{z}$ takimi programami jak AutoCAD, SketchUp i 3dsMax. Ma też na- kładkę do projektowania systemów nawodnienia. Jest to program autoryzowany przed AutoCAD, przez co jego wygląd i funkcjonalność jest łatwa do przyswojenia dla osób korzystających z oprogramowania firmy Autodesk.

- Vectorworks Landscape - oprogramowanie to ma podobną funkcjonalność do omówionych programów, również ma bogatą bibliotekę roślin oraz zaawansowane możliwości projektowania nawodnienia. Tym, co wyróżnia Vectorworks, jest wbudowane narzędzie Marionette, które umożliwia projektowanie parametryczne. Na dodatek jest to oprogramowanie BIM/GIS, co stanowi świetną podstawę do tworzenia złożonych koncepcji i dużej możliwości zastosowań (użyteczność GIS opisano w końcowej części artykułu). Jest to jedyny program wyróżniony ASLA, który został przetłumaczony na język polski.

Omówione oprogramowania stosowane przez architektów krajobrazu porównano ze sobą, przyjmując jako kryterium przydatności dla projektantów odniesienie do następujących aspektów: dostępność biblioteki roślin, wykorzystanie geolokalizacji, dostępność dodatkowej nakładki do projektowania systemu nawadniania roślin, dostępność BIM, możliwość wykorzystania projektowania parametrycznego oraz tłumaczenie na język polski (tab. 2). Względem każdego dokonano oceny, przyjmując dwustopniową

Tabela 2. Ocena programów wyróżnionych przez ASLA przeznaczonych dla architektów krajobrazu

Table 2. Evaluation of programs highlighted by ASLA dedicated to landscape architects

\begin{tabular}{|c|c|c|c|c|c|c|c|}
\hline $\begin{array}{l}\text { Nazwa programu } \\
\text { Name of program }\end{array}$ & $\begin{array}{l}\text { Biblioteki } \\
\text { roślin } \\
\text { Plant } \\
\text { libraries }\end{array}$ & $\begin{array}{l}\text { Geolokalizacja } \\
\text { Geolocation }\end{array}$ & $\begin{array}{l}\text { Nakładka } \\
\text { nawadnianie } \\
\text { Irrigation } \\
\text { overlay }\end{array}$ & BIM & $\begin{array}{c}\text { Projektowanie } \\
\text { parametryczne } \\
\text { Parametric } \\
\text { design }\end{array}$ & $\begin{array}{c}\text { Tłumaczenie } \\
\text { na język polski } \\
\text { Polish } \\
\text { translation }\end{array}$ & $\begin{array}{c}\text { Suma } \\
\text { Sum }\end{array}$ \\
\hline $\begin{array}{l}\text { KeySCAPE } \\
\text { LandCADD }\end{array}$ & 1 & 1 & 1 & 1 & 0 & 0 & 4 \\
\hline LAND F/X & 1 & 1 & 1 & 1 & 0 & 0 & 4 \\
\hline $\begin{array}{l}\text { Vectorworks } \\
\text { Landscape }\end{array}$ & 1 & 1 & 1 & 1 & 1 & 1 & 6 \\
\hline
\end{tabular}

\footnotetext{
${ }^{4}$ To inteligentny proces oparty na modelu 3D, który zapewnia architektom, inżynierom i specjalistom (AEC) wgląd i narzędzia umożliwiające bardziej wydajne planowanie, projektowanie, konstruowanie i zarządzanie budynkami i infrastrukturą (Autodesk, https://www.autodesk.com/solutions/bim [dostęp 14.12.2018]).
} 
skalę, w której: 0 pkt oznacza brak danego modułu w programie, a $1 \mathrm{pkt}$ - jego występowanie.

Wyniki porównania wskazuja, iż najwyższą ocenę uzyskał program Vectorworks Landscape, który wyróżnia się na tle innych programów zawartością wbudowanego narzędzia do projektowania parametrycznego oraz dostępnością wersji polskojęzycznej, co poprawia jego przystępność i stanowi znaczące udogodnienie dla polskich projektantów.

W przypadku wszystkich programów pewną niedogodnością jest to, iż bogate biblioteki roślin nie są jednak dostosowane do wymaganej szerokości geograficznej. $\mathrm{Z}$ tego powodu na polskim rynku zaczęły pojawiać się inne programy przeznaczone dla architektów krajobrazu. Są to m.in. Gardenphillia i DATAflor. Cześć architektów krajobrazu tworzy dokumentacje techniczną w programach $\mathrm{CAD}$, modeluja 3D w programie SketchUp oraz wykonuja postprodukcje oraz składanie plansz w programach Adobe Photoshop lub Adobe Illustrator. Osoby, które miały styczność $\mathrm{z}$ architekturą lub projektowaniem wnętrz, korzystają z programów Rhino z nakładką Lands Design lub z Autodesk Revit. Często osoby pracujace w gospodarce przestrzennej sięgają po QGIS lub ArcGIS.

Wybór stosowanego oprogramowania jest w każdym przypadku kwestią indywidualną - zależy od potrzeb, umiejętności projektanta i posiadanego dotychczas oprogramowania oraz możliwości finansowych.

\section{Narzędzia wspomagające projektowanie parametryczne}

Aby w pełni wykorzystywać narzędzie, jakim jest projektowanie parametryczne, potrzebna jest obszerna wiedza i doświadczenie projektanta, a także posiadanie zestawu wystarczających danych wejściowych oraz możliwości łączenia wszystkich zdobytych informacji w spójną całość. Pomimo że wymaga to wysokich kwalifikacji użytkownika, to połączenie narzędzi takich jak oprogramowanie BIM czy system informacji GIS wraz z oprogramowaniem służącym do projektowania parametrycznego oferuje bardzo dużo korzyści.
- System Informacji Geograficznej (ang. Geographical Information System) jest bardzo przydatnym narzędziem do mapowania i planowania przestrzeni w różnych skalach. Rozwój technologiczny sprawił, że informacje geograficzne są szeroko dostepne i stosunkowo latwe w analizie. GIS zawiera szerokie spektrum informacji dotyczących danych geograficznych. Dzięki takiemu oprogramowaniu można gromadzić, wprowadzać, analizować, przetwarzać i wizualizować dane (Paulson, 2017). GIS upowszechnia się $\mathrm{w}$ różnych narzędziach, również $\mathrm{w}$ dostępnych darmowo jak Geoportal.

- Oprogramowanie BIM (ang. Building Information Modelling) umożliwia integrowanie wiedzy na wielu płaszczyznach i komunikowanie jej ze soba. Jest to szeroko stosowane narzędzie w wielu dziedzinach. W projektowaniu zapewnia najlepszy sposób komunikacji zawartości projektu i jego składowych z konstruktorami i inwestorami. Stanowi więc coś więcej niż operowanie modelami 3D i czy oprogramowaniem CAD. Jest to technologia baz danych, która upraszcza informacje $i$ ich relacje w celu tworzenia interaktywnych modeli. Najczęściej proces ten sprowadza się to do tego, że zmiany naniesione na rzucie głównym są automatycznie aktualizowane we wszystkich płaszczyznach projektu - przekrojach, detalach, wizualizacjach, a także w kosztorysach. Dodatkowo, jeżeli po wprowadzeniu zmian występuja błędy lub nieprawidłowości, można je szybko wychwycić i naprawić. W wyniku stosowania BIM ogranicza się liczbę błędów w dokumentacji projektowej, ułatwiona jest współpraca między poszczególnymi działami projektowymi i etapami, redukuje się czas na przerysowywanie tych samych danych, a co za tym idzie - zmniejsza się koszt opracowania dokumentacji projektowej i skraca się czas jej wykonania (Gerber, 2007; Paulson, 2017).

Zarówno GIS, jak i BIM oferują bardzo wiele możliwości nie tylko w pozyskiwaniu danych, ale też ich obróbce. Po połączeniu obu narzędzi z projektowaniem parametrycznym można znacząco poprawić 
wydajność pracy projektowej i realizacyjno-wykonawczej m.in. poprzez usprawnienie komunikacji w zespole projektowym.

\section{WNIOSKI}

Projektowanie parametryczne może odegrać znaczącą rolę w projektowaniu obiektów architektury krajobrazu, podobnie jak w architekturze i designie. Dotyczy to nie tylko prognozowania zależności przyczynowo-skutkowych oraz symulacji zjawisk zachodzacych w przyrodzie oraz na terenach zurbanizowanych, ale też projektowania formy obiektu architektury krajobrazu z wykorzystywaniem powtarzalności elementu bazowego stanowiącego podstawę (moduł lub konkretne parametry stanowiące wartości graniczne) dla danej koncepcji. Potencjał tego narzędzia jest jednak obecnie wykorzystywany w małym zakresie przez architektów krajobrazu. Wynika to m.in. z małej dostępności oprogramowania opracowanego dla te grupy projektantów, co pociaga za sobą konieczność operowania wieloma programami obsługującymi branże pokrewne. Stanowi to utrudnienie $\mathrm{w}$ pracy architekta krajobrazu, generuje dodatkowe koszty i wydłuża czas pracy. Skutkuje to brakiem ekspertów w zakresie sprawnego korzystania z możliwości, jakie daje projektowanie parametryczne $\mathrm{w}$ dziedzinie architektury krajobrazu, a więc rozwiązań stosowanych w krajobrazie w jego różnych skalach.

Przeprowadzone analizy wskazują na potencjalnie największą użyteczność dla celów programowania parametrycznego $\mathrm{w}$ pracy architekta krajobrazu programów takich jak Autodesk 3ds Max, Rhino Grasshopper 3D, Marionette - Vectorworks oraz programu Vectorwoks Landscape. Jednak narzędzia do projektowania parametrycznego rozwijają się i ich dostępność jest coraz większa, co prawdopodobnie będzie wpływało na poszerzenie zakresu ich zastosowania w przyszłości.

\section{PIŚMIENNICTWO}

Amoroso, N. (2012). Digital landscape architecture now. London: Thames and Hudson.
Białozor, R. i Górski, M. (2018). Projektowanie parametryczne jako wspomaganie procesu projektowania konstrukcji. W M. Kijania-Kontak (red.), Nowoczesne projektowanie $i$ realizacja konstrukcji budowlanych (strony 111-117). Kraków: SKNKŻ CONKRET.

Charalampidis, E. i Tsalikidis, I. (2015). A parametric landscape design approach for urban green infrastructure development. W A. Gospodini (red.), Proceedings of the International Conference on Changing Cities II: Spatial, Design, Landscape \& Socio-economic Dimensions 22-26.06.2015, Porto Heli, Grece (strony 591-600). Thessaloniki: Grafima Publications.

Foremny, A. (2013). Wykorzystanie BIM w fazie wykonawczej przedsięwzięć budowlanych. Materiaty Budowlane, 496 (12), 82-85.

Gerber, D. (2007). Parametric Practices: Models for Design Exploration in Architecture (rozprawa doktorska). Cambridge MA: Harvard University.

Jabi, W. (2013). Parametric Design for Architecture. London: Laurence King.

Januszkiewicz, K. (2012). Architektura performatywna w Kolonii. Archiwolta, 2, 32-45.

Januszkiewicz, K. (2016). Projektowanie parametryczne oraz parametryczne narzędzia cyfrowe w projektowaniu architektonicznym. Architecturae et Artibus, 8 (3), 43-60.

Menges, A. (2006). Instrumental Geometry. Architectural Design, 76 (2), 42-83.

Nassery, F. i Sikorski, P. (2018). Nowe możliwości kształtowania elewacji z wykorzystaniem projektowania parametrycznego. Środowisko Mieszkaniowe, 23, 110-121. doi: 10.4467/25438700SM.18.040.9205

Nawrocka, A. A. (2013). Projektowanie parametryczne jako innowacyjna metoda w urbanistyce. Środowisko Mieszkaniowe, 12, 15-17.

Paulson, C. (2017). A study of the adaptation of parametric computer design among landscape architecture professionals in Texas (rozprawa doktorska). Arlington: University of Texas at Arlington.

Schumacher, P. (2009). Parametricism - A New Global Style for Architecture and Urban Design. AD Architectural Design - Digital Cities, 79 (4), 14-23.

Schumacher, P. (2016). Parametricism 2.0: Rethinking architecture's agenda for the 21st century. London: Artmedia.

Woodbury, R. (2010). Elements of Parametric Design. New York NY: Routledge. 


\section{TOOLS USED IN PARAMETRIC DESIGN IN LANDSCAPE ARCHITECTURE}

\section{ABSTRACT}

In the era of digitization, parametric design creates new possibilities for its application in areas such as architecture and design as well as landscape architecture. However, it requires tools that can not only facilitate the design process, but also reduce its time consumption. The purpose of the article is to review the software used for parametric design supporting the work of landscape architects. The selected, most popular programs and plugins used by architects and designers, which are also indirectly used by landscape architects as well as software dedicated directly to landscape architects, were evaluated. Most of the discussed software has options for parametric design, while they only apply to selected elements. Due to the interdisciplinary character of landscape architecture, there is currently no single multi-functional program giving the possibility of comprehensive application of parametric design options to all aspects of a complex project. For this reason, landscape architects are forced to combine functions themselves using several of programs. This is a significant difficulty in carrying out the design process.

Key words: parametric design, parametric modelling, digital parametric tools, design, landscape architect 